\title{
Education about sexual and gender minorities within Canadian emergency medicine residency programs
}

\author{
Robert Primavesi ${ }^{1}$ (D) Adam Burcheri ${ }^{2} \cdot$ Blair L. Bigham $^{3} \cdot$ Alexandre Coutin $^{4} \cdot$ Kelly Lien $^{5} \cdot$ Justin $\mathrm{Koh}^{6}$. \\ Michael Kruse ${ }^{7} \cdot$ Hilary MacCormick ${ }^{8} \cdot$ Scott Odorizzi $^{4} \cdot$ Victor $\mathrm{Ng}^{5} \cdot$ Vincent Poirier $^{1} \cdot$ Nadia Primiani $^{9} \cdot$ Sheila Smith $^{6}$. \\ Suneel Upadhye ${ }^{10} \cdot$ Clare Wallner $^{10} \cdot$ Judy Morris ${ }^{11} \cdot$ Rodrick Lim $^{5}$
}

Received: 23 October 2021 / Accepted: 16 November 2021 / Published online: 5 January 2022

( ) The Author(s), under exclusive licence to Canadian Association of Emergency Physicians (CAEP)/ Association Canadienne de Médecine d'Urgence (ACMU) 2022

\begin{abstract}
Objectives The CAEP 20212 SLGBTQIA $+{ }^{i}$ panel sought whether a gap exists within Canadian emergency medicine training pertaining to sexual and gender minority communities. This panel aimed to generate practical recommendations on improving emergency medicine education about sexual and gender minorities, thereby improving access to equitable healthcare. Methods From August 2020 to June 2021, a panel of emergency medicine practitioners, residents, students, and community representatives met monthly via videoconference. A literature review was undertaken, and three mixed methods surveys were distributed to the CAEP member list, CAEP Resident Section, College of Family Physicians of Canada (CFPC $)^{\text {iii }}$ Emergency Medicine Members Interest Group, and to emergency medicine residency program directors and their residents. Informed by the review and surveys, recommendations were drafted and refined by panel members before presentation at the 2021 CAEP Academic Symposium. A plenary was presented to symposium attendees composed of national emergency medicine community members, which reported the survey results and literature review. All attendees were divided into small groups to develop an action plan for each recommendation.

Conclusions The panel outlines eight recommendations for closing the curricular gap. It identifies three perceived or real barriers to the inclusion of sexual and gender minority content in emergency medicine residency curricula. It acknowledges three enabling recommendations that are beyond the scope of individual emergency medicine programs or emergency departments (EDs), that if enacted would enable the implementation of the recommendations. Each recommendation is accompanied by two action items as a guide to implementation. Each of the three barriers is accompanied by two action items that offer specific solutions to overcome these obstacles. Each enabling recommendation suggests an action that would shift emergency medicine towards sociocultural competence nationally. These recommendations set the primary steps towards closing the educational gap.
\end{abstract}

Keywords Emergency medicine $\cdot$ Social medicine $\cdot 2$ SLGBTQIA $+\cdot$ Cultural competence $\cdot$ Residency curriculum $\cdot$ Medical education $\cdot$ Sexuality $\cdot$ Gender $\cdot$ Justice $\cdot$ Equity $\cdot$ Diversity $\cdot$ Inclusion

Robert Primavesi

robert.primavesi@mcgill.ca

1 Montreal General Hospital, McGill University, 1650 Cedar Avenue, Room C2-101.7, Montreal, QC H3G1A4, Canada

2 Concordia University, Montreal, QC, Canada

3 Stanford University, Stanford, CA, USA

4 University of Ottawa, Ottawa, ON, Canada

5 Western University, London, ON, Canada
6 University of Saskatchewan, Saskatoon, SK, Canada

Queen's University, Kingston, ON, Canada

8 Dalhousie University, Halifax, NS, Canada

9 University of Toronto, Toronto, ON, Canada

10 McMaster University, Hamilton, ON, Canada

11 Université de Montréal, Montreal, QC, Canada 


\section{Résumé}

Objectifs Le panel ACMU 2021 2SLGBTQIA+ ${ }^{\mathrm{i}}$ a cherché à savoir s'il existe une lacune dans la formation en médecine d'urgence au Canada en ce qui concerne les communautés de minorités sexuelles et de genre. Ce panel visait à générer des recommandations pratiques sur l'amélioration de l'éducation en médecine d'urgence sur les minorités sexuelles et de genre, améliorant ainsi l'accès à des soins de santé équitables.

Méthodes D'août 2020 à juin 2021, un groupe de praticiens en médecine d'urgence, de résidents, d'étudiants et de représentants communautaires se sont réunis chaque mois par vidéoconférence. Une revue de la littérature a été entreprise et trois enquêtes à méthodes mixtes ont été distribuées à la liste des membres de l'ACMU, à la Section des résidents de l'ACMU, au Groupe d'intérêt des membres en médecine d'urgence du Collège des médecins de famille du Canada (CMFC) ${ }^{\text {iii }}$, ainsi qu'aux directeurs des programmes de résidence en médecine d'urgence et à leurs résidents. À la lumière de l'examen et des sondages, les recommandations ont été rédigées et peaufinées par les membres du comité avant d'être présentées au Symposium universitaire de l'ACMU de 2021. Une séance plénière a été présentée aux participants du symposium, composés de membres de la communauté nationale de la médecine d'urgence, qui ont fait état des résultats du sondage et de la revue de la littérature. Tous les participants ont été répartis en petits groupes afin d'élaborer un plan d'action pour chaque recommandation. Conclusions Le groupe d'experts formule huit recommandations pour combler le fossé entre les programmes d'enseignement. Il identifie trois obstacles perçus ou réels à l'inclusion du contenu sur les minorités sexuelles et de genre dans les programmes de résidence en médecine d'urgence. Il reconnait trois recommandations habilitantes qui dépassent la portée des programmes de médecine d'urgence individuels ou des services d'urgence (SU) et qui, si elles étaient adoptées, permettraient la mise en œuvre des recommandations. Chaque recommandation est accompagnée de deux mesures de suivi comme guide de mise en œuvre. Chacun des trois obstacles est accompagné de deux éléments d'action qui offrent des solutions spécifiques pour surmonter ces obstacles. Chaque recommandation habilitante suggère une action qui ferait évoluer la médecine d'urgence vers une compétence socioculturelle au niveau national. Ces recommandations établissent les principales étapes pour combler l'écart en matière d'éducation.

\section{Introduction}

Emergency physicians and residents play a vital role in caring for and advocating for vulnerable populations. For many, the emergency department (ED) is the only source of accessible primary medical care. Due to socioeconomic factors, sexual and gender minority individuals are more likely to require healthcare services, and less likely to have healthcare coverage than cis-gender (cis) and heterosexual populations [1]. Sexual and gender minorities are more likely to have chronic conditions and often lack competent healthcare providers, leading to delayed care through discriminate aversion or via unnecessary serial referrals to specialized care with long waitlists $[2,3]$. This is directly related to the high rates (7.4-47\%) of ED avoidance or inability to obtain care [3]. The misinformed, the uninformed, the well-intentioned, and the malicious physician all contribute to these inequities.

There are many steps to take before making recommendations towards sociocultural competent postgraduate emergency medicine training. First, we must acknowledge a curricular gap. A concern for the lack of curricular focus on 2SLGBTQIA + issues has been raised within residency programs by the American Medical Association (AMA) as early as 1994 [4]. Second, a need and willingness to fill the educational gap must be established. A 2016 study showed a positive correlation between resident preparedness, sexual and gender minority individuals accessing timely and competent care, and better health outcomes [5]. With increasing visibility comes increased exposure to sexual and gender minority patients, creating a much higher need for properly trained healthcare professionals.

Although the importance and motivation for change are demonstrable, barriers to equitable healthcare must be overcome. Institutional policies and resources dedicated to sexual and gender minority care are lacking. Even small changes such as gender-neutral washrooms strongly affect transgender (trans) patients' comfort and trust in healthcare providers, yet they are rare [6]. The lack of policy partially emerges from the paucity of curricular content in Canadian emergency medicine programs [3]. As of 2014, only 33\% of emergency medicine residency curricula incorporated topics on sexual and gender minority care [7]. One third of surveyed American emergency medicine residents felt 'neutral' to 'very uncomfortable' addressing sexual and gender minority patient needs [8]. The practical recommendations herein will guide the closure of the identified gap, yielding better equipped future emergency physicians.

\section{Methods}

\section{Literature review}

A literature search was performed using Google Scholar, Medline, and PubMed databases. The search started in November 2020 and was completed in March 2021. Search 
terms used include emergency medicine, social medicine, 2SLGBTQIA +, 2SLGBTQIA + residency programs, 2SLGBTQIA + medical education, 2SLGBTQIA + residency curriculum, equity, diversity, and inclusion. The final literature review includes 73 Canadian and American articles. A list of definitions for terms used in this article is listed in Table 1.

\section{Surveys}

Three anonymous surveys were adapted from prior analogous work by MacCormick and colleagues in obstetric anesthesia to target emergency medicine faculty, residents, and program directors [9]. These surveys worked to gather data about sexual and gender minority related curricular content within their programs. Questions addressed demographics, the existence of formalized policies and educational content regarding the care and needs of sexual and gender minorities, the personal experiences and comfort in providing care to sexual and gender minority patients or in supervising residents who provide this care, perceived need for curricular or faculty development, and barriers to inclusion within respective curricula.
We included a convenience sample of CAEP physicians and residents, program directors, the CFPC Emergency Medicine Members Interest Group, and asked program directors to distribute the survey to their residents. Survey highlights are featured in Table 2.

\section{Forming recommendations}

Based on the literature review and surveys, the panel members each generated five recommendations. Eleven of fifteen panel members participated, yielding 55 recommendations that were grouped around nine themes and consolidated into nine recommendations.

\section{Creation of an action plan}

The panel presented results of the project at the 2021 CAEP Academic Symposium on Equity, Diversity, and Inclusion, including concepts, panel members, goals, survey findings, and a summary of the literature review. Attendees were separated into nine small working groups including a moderating panel member. Each group was asked to generate two action

Table 1 Definitions

i. 2SLGBTQIA + : an acronym for two-spirit, lesbian, gay, bisexual, transgender, queer, intersex and asexual, while + stands for other ways individuals express their gender and sexuality outside heteronormativity and the gender binary

ii. Sexual and Gender Minorities (SGMs): An inclusive, albeit broad acronym, that represents all non-cisgender and/or non-heterosexual communities. This encompasses the 2SLGBTQIA + communities. The health inequities affecting individual members of the SGM communities vary widely

iii. College of Family Physicians of Canada (CFPC): A professional association and the legal certifying body for the practice of family medicine in Canada, founded in 1954

iv. Tokenism: the practice of making only a perfunctory or symbolic effort to do a particular thing, especially by recruiting a small number of people from underrepresented groups to give the appearance of sexual or racial equality within a workforce

v. Intersectionality: the interconnected nature of social categorizations such as race, class, and gender as they apply to a given individual or group, regarded as creating overlapping and interdependent systems of discrimination or disadvantage

vi. Mentorship: a relationship between two people where the individual with more experience, knowledge, and connections can pass along what they have learned to a more junior individual within a certain field

vii. Allyship: a lifelong process of building relationships based on trust, consistency, and accountability with marginalized individuals and/or groups of people

viii. Cultural humility: having an interpersonal stance that is other-oriented rather than self-focused, characterized by respect and lack of superiority toward an individual's cultural background and experience

ix. Royal College of Physicians and Surgeons of Canada (RCPSC): A regulatory college which acts as a national, non-profit organization established in 1929 by a special Act of Parliament to oversee the medical education of specialists in Canada

$\mathrm{x}$. Implicit bias: bias that results from the tendency to process information based on unconscious associations and feelings, even when these are contrary to one's conscious or declared beliefs

xi. Justice, Equity, Diversity, and Inclusion (JEDI): justice seeks to dismantle the barriers to opportunities and systemic disadvantages to people's ability to access resources and opportunities. Equity ensures everyone has access to equivalent opportunities and resources so that there is an equal opportunity to thrive. Diversity encompasses the differences among us based on what we experience or encounter in access to opportunities and resources. Inclusion means fostering respect and a team spirit in the workplace and embracing and amplifying multicultural perspectives and voices

xii. Minority tax: the burden of extra responsibilities placed on minority faculty in the name of diversity

xiii. Sponsorship: senior colleagues advocate on sponsored employees' behalf, helping guide them through high-profile career changes in an organization

xiv. Service Learning: a form of experiential education where learning occurs through a cycle of action and reflection as learners seek to achieve real objectives for the community and deeper understanding and skills for themselves 
Table 2 Highlights of survey results

\section{Faculty Survey}

$\mathrm{N}=169$ (CAEP email list 1455 + CFPC EM MIG $829=2284)$

$71 \%$ urban academic centres

$65 \%$ teach both RCPSC and CFPC EM residents

\begin{tabular}{|c|c|c|c|c|c|}
\hline & YES & NO & UNSURE & $\begin{array}{r}\text { NOT } \\
\text { APPLICABLE }\end{array}$ & TOTAL \\
\hline $\begin{array}{l}\text { 4D. Does your current residency curriculum } \\
\text { address the needs of SGM populations, } \\
\text { specifically? }\end{array}$ & $23 \%$ & $29 \%$ & $48 \%$ & $1 \%$ & 154 \\
\hline $\begin{array}{l}\text { 4E. Do the emergency physicians at your } \\
\text { institution receive any cultural competency } \\
\text { training as part of the department orientation? }\end{array}$ & $12 \%$ & $70 \%$ & $18 \%$ & $0 \%$ & 154 \\
\hline $\begin{array}{l}\text { 5. If you answered "yes" to the previous } \\
\text { question (4E), does the culturalcompetency } \\
\text { training offered at your institution address issues } \\
\text { specific to SGM communities? }\end{array}$ & $6 \%$ & $15 \%$ & $23 \%$ & $0 \%$ & 101 \\
\hline $\begin{array}{l}\text { 17. Do you think your curriculum adequately } \\
\text { prepares your residents to provide care to SGM } \\
\text { patients? }\end{array}$ & $12 \%$ & $31 \%$ & $51 \%$ & $6 \%$ & 146 \\
\hline $\begin{array}{l}\text { 18. In the future, would you like to see } \\
\text { more SGM content incorporated into } \\
\text { your program's curriculum? }\end{array}$ & $70 \%$ & $8 \%$ & $18 \%$ & $5 \%$ & 146 \\
\hline \multicolumn{6}{|c|}{ EM = Emergency Medicine, MIG = Member Interest Group, $\mathrm{SGM}$ = sexual and gender minority } \\
\hline $\begin{array}{l}\text { Resident Survey } \\
N=49 \\
25 \text { RCPSC } \\
24 \text { CFPC }\end{array}$ & & & & & \\
\hline & YES & NO & UNSURE & $\begin{array}{r}\text { NOT } \\
\text { APPLICABLE }\end{array}$ & TOTAL \\
\hline $\begin{array}{l}\text { 6D. Does your current residency } \\
\text { curriculum address the needs of SGM } \\
\text { populations, specifically? }\end{array}$ & $32 \%$ & $50 \%$ & $15 \%$ & $2 \%$ & 40 \\
\hline $\begin{array}{l}\text { 10. Do you think your curriculum } \\
\text { adequately prepares you to provide care to } \\
\text { SGM patients? }\end{array}$ & $15 \%$ & $52 \%$ & $30 \%$ & $2 \%$ & 40 \\
\hline $\begin{array}{l}\text { 20. In the future, would you like to see } \\
\text { more SGM content incorporated into your } \\
\text { program's curriculum? }\end{array}$ & $77 \%$ & $15 \%$ & $8 \%$ & $0 \%$ & 39 \\
\hline
\end{tabular}

Program Director Survey

$\mathrm{N}=17$ (14 RCPSC, 17 CCFP-EM, 1 combined FM/EM programs in Canada)

8 RCPSC

\begin{tabular}{|l|r|r|r|r|r|}
\hline 9 CFPC & YES & No & UNSURE & $\begin{array}{r}\text { NOT } \\
\text { APPLICABLE }\end{array}$ & TOTAL \\
\hline $\begin{array}{l}\text { 6D. Does your current residency } \\
\text { curriculum address the needs of SGM } \\
\text { populations, specifically? }\end{array}$ & $43 \%$ & $57 \%$ & $0 \%$ & $0 \%$ & 14 \\
\hline $\begin{array}{l}\text { 10. Do you think your curriculum } \\
\text { adequately prepares your residents to } \\
\text { provide care to SGM patients? }\end{array}$ & $7 \%$ & $57 \%$ & $36 \%$ & $0 \%$ & 14 \\
\hline $\begin{array}{l}\text { 11. In the future, would you like to see } \\
\text { more SGM content incorporated into your } \\
\text { program's curriculum? }\end{array}$ & $71 \%$ & $0 \%$ & $29 \%$ & $0 \%$ & 14 \\
\hline SGM = sexual and gender minority & & & & & \\
\hline
\end{tabular}

items that would ease the implementation of their assigned recommendation.

After the symposium, the video recording from the symposium, along with field notes from moderators, were collated to further refine the action items. The final recommendations and action plan were vetted by the panel members and community representatives. One recommendation was eliminated because the action items were redundant. Eight recommendations, each with two action items for implementation, are presented in Table 3. The evidence for these recommendations is presented below.

The same three barriers to implementation of a sexual and gender minority curriculum in Canadian emergency medicine residency programs were identified by the faculty, resident, and program director surveys. These barriers were also seen throughout the literature review. Two action items for each barrier were generated by surveying the panel members. They are presented in Table 4. 
Table 3 Summary of Recommendations with Action Items

Recommendation 1: Curriculum. Canadian emergency medicine residency programs should have dedicated teaching about sexual and gender minority $(\mathrm{SGM})^{\mathrm{ii}}$ topics as they pertain to emergency care, with the aim of improving unique health outcomes for sexual and gender minority patients

Action items:

1. Integrate mandatory education on sexual and gender minority topics into the curriculum

2. Integrate sexual and gender minority stories/personas into all types of cases. The focus should be on sexual and gender minority representation as the norm in educational materials, but not have the issue be specifically about the sexual and gender minority identities or experience

Recommendation 2: Resident Selection. Canadian emergency medicine programs should achieve representation within resident selection that reflects the diversity of sexual and gender minorities in Canada. These efforts should be mindful of tokenism ${ }^{\text {iv }}$ and of intersectionality ${ }^{\mathrm{v}}$ with other underrepresented groups in emergency medicine. Sexual and gender minority representation should include Black, Indigenous, and other people of colour (BIPOC)

Action items:

1. Oblige selection committee members to complete implicit bias ${ }^{\mathrm{x}}$ training. File review should be blinded as much as possible. After the process is complete, the committee should reflect on selected residents as a group to address biases

2. Use language for online program descriptions that reflect the Justice, Equity, Diversity, and Inclusion (JEDI) ${ }^{\mathrm{xi}}$ objectives of the program. This should include a language of acceptance and belonging that creates safer spaces for applicants. This language should foster an environment where applicants are comfortable disclosing their sexual and gender minority status without being asked

Recommendation 3: Faculty Recruitment. Canadian emergency departments (EDs) should achieve representation within their faculty that reflects the diversity of sexual and gender minorities in Canada. These efforts should be mindful of tokenism and of intersectionality with other underrepresented groups in emergency medicine. Sexual and gender minority representation should include Black, Indigenous, and other people of colour (BIPOC)

Action items:

1. Promote the diversity that exists within faculty and senior leadership to create safer spaces for applicants. Diversity statistics, stories, and backgrounds should be disclosed, recognized, and disseminated to potential hires to foster an environment for comfortable self-disclosure and build capacity for people from underrepresented groups

2. Recruit faculty from diverse groups in a transparent and deliberate way. While respecting human resource requirements, this should be done by including diversity in the selection panels and placing merit on diversity in applicant portfolios

Recommendation 4: Mentorship ${ }^{\text {vi }}$. Canadian emergency medicine programs should provide mentors for residents who identify as sexual and gender minorities

Action items:

1. Include mentors who identify as sexual and gender minorities and those with educated allyship ${ }^{\text {vii }}$ to reduce the burden of a minority tax ${ }^{\text {xii }}$. Mentors should be extended resources, rewards, and compensation. Mentors can be within a program/faculty or cross-specialty and interinstitutional if they are qualified

2. Create a sponsorship ${ }^{x i i i}$ program where emergency medicine leaders actively advocate for opportunities for sexual and gender minority residents and faculty

Recommendation 5: Faculty. Canadian academic EDs should identify at least one content expert in the care of sexual and gender minorities who is either a member of the sexual and gender minority community or has a strong history of allyship to the community. Given the diversity of sexual and gender minority communities, identifying multiple experts is encouraged

Action items:

1. Create a formal academic job description including expectations, benefits and/or monetary compensation to provide resources and credibility to this position. The person in this position would take part in education and implementation of protocols and strategies

2. Extend ongoing faculty development, leadership training, and support to this position

Recommendation 6: Faculty and Staff Professional Development. Canadian EDs, with and without academic affiliation, should ensure faculty and staff are educated about sexual and gender minority health issues with a focus on cultural humility ${ }^{\text {viii }}$ and an understanding of what accessibility means for these communities. This education should be undertaken so that all staff can apply these principles to patients and learners in their departments

Action items:

1. Mandate education on sexual and gender minority health and social issues by tying it to appointment/reappointment processes, privileges, and advancement within the department/institution

2. Provide visibility to identify those who undertook this education (e.g., signage, lanyards, stickers, pins, pronoun identifiers) to deliver cues to patients and staff about who can provide support and safer spaces for sexual and gender minorities. Caution should be taken to make it clear that appearing to be an ally without the appropriate professional and personal development is unethical and can be harmful

Recommendation 7: Community engagement. Canadian emergency medicine programs should include members of the sexual and gender minority community, including Black, Indigenous, and other people of colour (BIPOC), at all stages of curriculum development and implementation. This reflects the principle of "Nothing about us, without us" 
Table 3 (continued)

Action items:

1. Involve sexual and gender minority community members at every level of curricular review, design, implementation, and evaluation processes. Avoid applying a minority tax by relying on staff who identify as sexual and gender minorities to represent the community. This can be done by connecting with national groups that represent the interests of sexual and gender minority populations. Draw on recruitment success from other underrepresented groups within the hospital system to inform community outreach strategies and acknowledge intersectionality

2. Establish criteria for what constitutes a 'community member' while being mindful of community needs and how communities want to be represented. Train external members to provide feedback and guidance. This role should be compensated

Recommendation 8: Practice Environment. All Canadian EDs should establish program and departmental policies that support and advocate for sexual and gender minority learners, faculty members, employees, and patients. This should be done through staff orientation, training, and reporting policies

Action items:

1. Include SGM policies in faculty and staff contracts during the hiring and advancement processes and strictly enforce these throughout education and employment

2. Offer a psychologically safe reporting mechanism. This should allow for anonymity and ongoing safety, while documenting microaggressions and discrimination, with the goal of making specific culture change. These reports should be reviewed, supported, and empowered by an impartial person (ombudsman), while abiding by union rules

Table 4 Barriers with action plan

Barrier 1: Perceived lack of time in the curriculum

Action items:

1. Integrate sexual and gender minority stories/personas into existing curricular material instead of creating new content so that the total number of hours is not increased. The focus should be on sexual and gender minority representation as the norm in educational materials, but not have the issue be specifically about the sexual and gender minority identities or experience. See Recommendation 1

2. Encourage activities that are not formal didactic learning, such as service learning ${ }^{\text {xiv }}$ that combines learning objectives with community service to provide an understanding of context while meeting societal needs

Barrier 2: Perceived lack of need vs. real (assessed) need

Action items:

1. Recruit community members with lived experiences to provide narratives of misapprehension and barriers experienced in their visits to the ED. Offering a tangible patient story can humanize the issues and spark introspection and change

2. Emphasize knowledge translation for the existing evidence of the needs of sexual and gender minority populations. The idea that people know how to care for sexual and gender minority patients without any education comes from a knowledge gap

Barrier 3: Lack of faculty to teach

Action items:

1. Recruit sexual and gender minority faculty and empower allies. See Recommendation 5. Develop a training program for faculty educators and incentivize training in sexual and gender minority health and JEDI through course sponsorship, protected time off for training, to develop core expert competencies. Consider bringing in community members to teach or co-teach sessions with medical faculty. Use non-physician faculty from nursing and other allied health disciplines more effectively

2. Partner with other faculties to develop a "train the trainer" program and/or develop online content to do virtual training

Table 5 Enabling recommendations

Enabling Recommendation 1: National Recommendations. National emergency medicine leadership and education partners should support the implementation of recommendations on education about sexual and gender minorities in Canadian emergency medicine residency programs

Enabling Recommendation 2: Accreditation/National Standards. The Royal College of Physicians and Surgeons of Canada (RCPSC) ${ }^{\text {ix }}$ and the College of Family Physicians of Canada (CFPC) $)^{\text {iii }}$ should establish competencies pertaining to the care of sexual and gender minorities, along with guidelines for Canadian emergency medicine programs to establish the requisite curricula to ensure learners meet these competencies

Enabling Recommendation 3: National Curriculum. There should be national guidelines and a national repository of resources for curriculum development for both the RCPSC and CFPC emergency medicine programs 
Finally, we identified three enabling recommendations that are beyond the scope of individual emergency medicine residency programs or departments. If implemented on a national level, these enabling recommendations would facilitate the implementation of sexual and gender minority curricula (Table 5).

\section{Summary of recommendations, barriers, and enabling recommendations}

Recommendation 1: Curriculum Canadian emergency medicine residency programs should have dedicated teaching about sexual and gender minority topics as they pertain to emergency care, with the aim of improving unique health outcomes for sexual and gender minority patients.

While the time devoted to sexual and gender minority content is either non-existent or insufficient to cover the specific needs of each diverse community, programs that do incorporate sexual and gender minority content do so in a manner that makes sexual and gender minority identities the clinical focus. On average, 2SLGBTQIA + curricular content comprised $5 \mathrm{~h}$ during the entirety of residency while a third of programs reported no time was spent on this content whatsoever [10]. This recommendation allows for both clinical competence and representation within a competency-based framework.

Recommendation 2: Resident Selection Canadian emergency medicine programs should achieve representation within resident selection that reflects the diversity of sexual and gender minorities in Canada. These efforts should be mindful of tokenism ${ }^{\text {iv }}$ and of intersectionality ${ }^{\mathrm{v}}$ with other underrepresented groups in emergency medicine. Sexual and gender minority representation should include Black, Indigenous, and other people of colour (BIPOC).

Achieving representation within residency through diverse resident selection is crucial to generating advocacy from within. In an initiative to bridge the educational gap, a main objective and systemic recommendation from Kosman and colleagues is to recruit sexual and gender minorities into the field [11]. This recommendation would help foster activism throughout post-graduate education and allow a more representative emergency medicine faculty and leadership in the future.

Recommendation 3: Faculty Recruitment Canadian EDs should achieve representation within their faculty that reflects the diversity of sexual and gender minorities in Canada. These efforts should be mindful of tokenism and of intersectionality with other underrepresented groups in emergency medicine. Sexual and gender minority representation should include Black, Indigenous, and other people of colour (BIPOC).
A representative emergency medicine resident selection process can ensure that future faculty are active advocates for bridging the curricular gap, while diverse faculty recruitment makes change more tangible in the present. Oftentimes, faculty that are willing to create better health outcomes for sexual and gender minority individuals lack enough experience or expertise [12]. A recommendation for faculty recruitment allows for the focus of health equity to be on perpetuating culturally competent knowledge through diverse representation instead of the willingness of the less informed.

Recommendation 4: Mentorship ${ }^{v i}$ Canadian emergency medicine programs should provide mentors for residents who identify as sexual and gender minorities.

Mentorship is important for both personal growth for residents and for a dedicated coalition towards the goal of academic inclusion. The Cambridge Health Alliance (CHA) in Massachusetts recognizes that exposure to health advocacy role models and mentors plays an important role in resident development, empowerment, and active advocacy [13]. Mentorship allows for the expansion of the body of knowledge on sexual and gender minority related health information by creating opportunities and support during the research process.

Recommendation 5: Faculty Canadian academic EDs should identify at least one content expert in the care of sexual and gender minorities who is either a member of the sexual and gender minority community or has a strong history of allyship ${ }^{\text {vii }}$ to the community. Given the diversity of sexual and gender minority communities, identifying multiple experts is encouraged.

Having an expert to oversee academic progression is important when moving towards the development of novel curricula. One of the most cited barriers is the real or perceived lack of experts in the field $[2,14]$. Having a designated faculty expert allows for the oversight and direction needed to overcome this barrier and to guide non-experts towards educated allyship.

Recommendation 6: Faculty and Staff Professional Development Canadian EDs, with and without academic affiliation, should ensure faculty and staff are educated about sexual and gender minority health issues with a focus on cultural humility ${ }^{\text {viii }}$ and an understanding of what accessibility means for these communities. This education should be undertaken so that all staff can apply these principles to patients and learners in their departments.

Faculty and staff educational development are not uncommon yet are lacking for sexual and gender minority topics. Studies have shown that there is a decline in idealism and interest in social issues as students and residents progress through medical training [15]. This is not the case for sexual and gender minority content as educators, faculty, and learners are unanimous on the importance of 
cultural competence training [7], which has been shown to reduce stigmatization, improve communication, and improve patient outcomes $[4,16]$.

Recommendation 7: Community engagement Canadian emergency medicine programs should include members of the sexual and gender minority community, including Black, Indigenous, and other people of colour (BIPOC), at all stages of curriculum development and implementation. This reflects the principle of "Nothing about us, without us".

Engaging an expert in the development and implementation of a novel curriculum and in academic advancement is crucial but, in practice, diverse community engagement is necessary. The inclusion of community representatives at all levels allows the end-product to incorporate the perspectives and needs of the communities affected.

Recommendation 8: Practice Environment All Canadian EDs should establish program and departmental policies that support and advocate for sexual and gender minority learners, faculty members, employees, and patients. This should be done through staff orientation, training, and reporting policies.

Program and departmental policies should have very specific instructions on how to institutionalize advocacy. Position statements and calls to action are notable in that they are generalized recommendations, but they are no longer enough. In our survey, over $90 \%$ of emergency medicine staff stated their department did not have any formalized policies for sexual and gender minority care or were unsure. Having clear and strict formalized guidelines, instead of recommendations, creates an air of decisiveness that makes residents and physicians aware of their duty to support and advocate for sexual and gender minority learners, faculty members, employees, and patients.

\section{Barriers}

The three common barriers identified among our surveys were: (1) Perceived lack of time in the curriculum, (2) perceived lack of need vs. real (assessed) need, and (3) lack of faculty to teach. These are the most cited barriers to the development and implementation of culturally competent curricula across specialties and at every level of education $[2,9,14]$. A major limitation to the identification of perceived and literal barriers, is the absence of literature describing sexual and gender minority patient perspectives [9]. Although more research into this would inform how to overcome these barriers, this panel identified two action items per barrier. These action items give insight into which needs must be met to navigate these perceived obstacles most efficiently. Two of the three barriers are perception-based because it is unknown whether the barriers are real or if it is an expression of "veiled opposition" [9]. The scope of our surveys was not able to explore this specifically. Evidently, the barrier of having a lack of faculty to teach sexual and gender minority content is real and can be overcome. Adhering to these recommendations is a step in the right direction to overcoming these barriers.

\section{Enabling recommendations}

Enabling Recommendation 1: National Recommendations National emergency medicine leadership and education partners should support the implementation of recommendations on education about sexual and gender minorities in Canadian emergency medicine residency programs.

Tangible change can only begin once everyone is onboard. The advocacy and support of leadership across Canadian emergency medicine departments and programs would not only start the conversation but set the cultural competency standards for everyone involved with sexual and gender minority care. National leadership will influence and guide all members of the emergency medicine community towards better educational standards.

Enabling Recommendation 2: Accreditation/National Standards The Royal College of Physicians and Surgeons of Canada (RCPSC) ${ }^{\mathrm{ix}}$ and CFPC should establish competencies pertaining to the care of sexual and gender minorities, along with guidelines for Canadian emergency medicine programs to establish the requisite curricula to ensure learners meet these competencies.

As of 2021, the RCPSC, the CFPC, and the Accreditation Council for Graduate Medical Education (ACGME) do not include any sexual and gender minority related content in their required learning competencies for emergency medicine residency programs $[17,18]$. The deficit of accreditation board-established competencies can be considered a significant enabler for the lack of development and implementation of sexual and gender minority curricular content. Internationally, increasing medical education around trans health is in line with the World Health Organization (WHO) 2030 agenda for sustainable development [19].

Enabling Recommendation 3: National Curriculum There should be national guidelines and a national repository of resources for curriculum development for both the RCPSC and CFPC emergency medicine programs.

A national network of shared best-practice guidelines and resources would greatly affect the speed of curricular development. According to emergency physicians, poor availability of learning resources is a very important barrier to increasing knowledge on sexual and gender minority care [20]. Having 
an established network of communication and a repository of resources would allow for a prompt implementation of a sexual and gender minority curriculum and would help in oversight, evaluation, and troubleshooting.

\section{Conclusions}

We present eight recommendations to close the emergency medicine educational gap pertaining to sexual and gender minorities, three barriers to the development of a critically conscious and sociocultural competent curriculum, and three enabling recommendations that would help implement national sexual and gender minority educational standards. In this, we formed an action plan that can facilitate the implementation of our recommendations through specific instruction and that help navigate specific barriers. The implementation of our recommendations should serve as the foundation of a movement towards equitable, diverse, inclusive postgraduate emergency medicine curricula, and more competent emergency physicians in general. Given the ED is oftentimes the sole source of accessible care for marginalized peoples, the emergency medicine community is primed to employ our recommendations to improve the care of sexual and gender minorities throughout our healthcare systems.

Acknowledgements We wish to acknowledge Christopher Cheung, Anaesthesia resident at Dalhousie University, whose study on Education About Sexual and Gender Minorities (SGM) Within Canadian Anaesthesia Residency Programs inspired our research and served as the foundation for the development of our surveys. We wish to acknowledge Karen B.K. Chan and Rahim Thawer (University of Toronto) for representing the 2 SLGBTQIA+ community, vetting our surveys, and providing external validity to our recommendations and action plans.

Financial support None.

\section{Declarations}

Conflict of interest The authors declare no competing interests.

\section{References}

1. Downing JM, Przedworski JM. Health of transgender adults in the US, 2014-2016. Am J Prev Med. 2018;55:336-44.

2. Alexa M, Ken T, Stephen HF, Karine K, Margaret LL, Amy R. Gender diversity training in Canadian paediatric postgraduate medical education: a needs assessment survey. Paediatrics \& Child Health. 2019.

3. Kruse MI, Bigham BL, Voloshin MW, Clarizio A, Upadhye S. Care of sexual and gender minorities in the emergency department: a scoping review. Ann Emerg Med. 2021 (In press).

4. Kelley L, Chou CL, Dibble SL, Robertson PA. A critical intervention in lesbian, gay, bisexual, and transgender health: knowledge and attitude outcomes among second-year medical students. Teach Learn Med. 2008;20(3):248-53. https://doi.org/10.1080/10401 330802199567.

5. Winter S, Diamond M, Green J, Karasic D, Reed T, Whittle S, et al. Transgender people: health at the margins of society. Lancet. 2016;388(10042):390-400.

6. Vance SR Jr, Halpern-Felsher BL, Rosenthal SM. Health care providers' comfort with and barriers to care of transgender youth. J Adolesc Health. 2015;56(2):251-3.

7. Moll J, Krieger P, Moreno-Walton L, et al. The prevalence of lesbian, gay, bisexual, and transgender health education and training in emergency medicine residency programs: what do we know? Acad Emerg Med. 2014;21(5):608-11. https://doi.org/10.1111/ acem. 12368 .

8. Moll J, Krieger P, Heron SL, Joyce C, Moreno-Walton L. Attitudes, behavior, and comfort of emergency medicine residents in caring for LGBT patients: what do we know? AEM Educ Train. 2019;3(2):129-35. https://doi.org/10.1002/aet2.10318.

9. MacCormick H, George RB. Sexual and gender minorities educational content within obstetric anesthesia fellowship programs: a survey. Can J Anesth/J Can Anesth. 2020;67:532-40. https://doi. org/10.1007/s12630-019-01562-x.

10. Obedin-Maliver J, Goldsmith ES, Stewart L, et al. Lesbian, gay, bisexual, and transgender-related content in undergraduate medical education. JAMA. 2011;306:971-7.

11. Kosman KA, Ahn Allen CG, Fromson JA. A call to action: the need for integration of transgender topics in psychiatry education. Acad Psychiatry. 2019;43(1):82-8. https://doi.org/10.1007/ s40596-018-0966-7.

12. Coutin A, Wright S, Li C, Fung R. Missed opportunities: are residents prepared to care for transgender patients? A study of family medicine, psychiatry, endocrinology, and urology residents. Can Med Educ J. 2018;9(3):e41-55 (Published 2018 Jul 27).

13. Basu G, Pels RJ, Stark RL, Jain P, Bor DH, McCormick D. Training internal medicine residents in social medicine and researchbased health advocacy: a novel, in-depth curriculum. Acad Med. 2017;92(4):515-20. https://doi.org/10.1097/ACM.0000000000 001580.

14. Daniel H, Butkus R. Health and public policy Committee of the American College of Physicians: Lesbian, Gay, Bisexual, and Transgender health disparities: executive summary of a policy position paper from the American College of Physicians. Ann Intern Med. 2015;163:135-7.

15. Price J, Price D, Williams G, Hoffenberg R. Changes in medical student attitudes as they progress through a medical course. J Med Ethics. 1998;24:110-7.

16. Khalili J, Leung LB, Diamant AL. Finding the perfect doctor: identifying lesbian, gay, bisexual, and transgender-competent physicians. Am J Public Health. 2015;105(6):1114-9. https://doi.org/ 10.2105/AJPH.2014.302448.

17. Counselman FL, Babu K, Edens MA, et al. The 2016 model of clinical practice of emergency medicine. J Emerg Med. 2017;52:846-9.

18. General Content of Core Training. Emergency Medicine Competencies. 2008. https://www.royalcollege.ca/rcsite/documents/ibd/ emergency-medecine-competencies-e.pdf. Accessed Sept 2021

19. Hana T, Butler K, Young LT, Zamora G, Lam JSH. Transgender health in medical education. Bull World Health Organ. 2021;99(4):296-303. https://doi.org/10.2471/BLT.19.249086.

20. Lien K, Vujcic B, Ng V. Attitudes, behaviour, and comfort of Canadian emergency medicine residents and physicians in caring for 2SLGBTQI+ patients. CJEM. https://pubmed.ncbi.nlm.nih. gov/34363194/. 